\title{
INFRARED IMAGING AND COMPUTERIZED TOMOGRAPHY IN BREAST CANCER: CASE STUDY
}

\author{
C. Dalmaso Neto ${ }^{a}$, ABSTRACT \\ J. V. C. Vargas ${ }^{a}$, \\ and M. L. Brioschi ${ }^{\mathrm{b}}$ \\ This work presents a case study of a 75 -year-old woman breast with \\ cancer. The investigation process used infrared image, mammography, \\ computerized tomography (CT) and ultrasound guided biopsy to

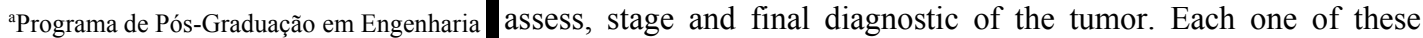 \\ Mecânica, Departamento de Engenharia evaluations brings an isolated piece of information that results in the \\ Mecânica, Departamento de Engenharia \\ correct diagnostic, and treatment. As early diagnostic of breast cancer \\ Mecânica, Universidade Federal do Paraná, \\ UFPR, Curitiba, PR, 81531-980, Brazi

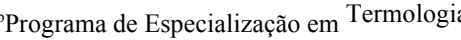 \\ e Termografia, Hospital das Clínicas da \\ Faculdade de Medicina da Universidade de \\ São Paulo, HCFMUSP, São Paulo, SP, \\ 01246-903, Brazil vargasjvcv2@gmail.com \\ dalmasont@gmail.com \\ marcosbrioschi@gmail.com \\ Received: Feb 15, 202 \\ Revised: Feb 20, 2021 \\ Accepted: Mar 10, 2021 Keywords: infrared imaging, computerized tomography, blood flow
}

\section{INTRODUCTION}

Currently, early diagnosis of breast cancer is the most important single action modern medicine has to decrease female mortality rates, as mortality from breast cancer is mainly linked to access to diagnosis and adequate treatment in a timely manner. INCA, 2015 states that ultrasonography and mammography are the elected imaging method in the diagnostic investigation of suspected breast abnormalities, and other image analyzes can be used, such as magnetic resonance imaging or tomography in order to provide anatomical information about the tumor, and biopsies are used for correct staging, next to surgical procedures, as well as radiotherapy or chemotherapy. Most breast tumors are invasive and can infiltrate other tissues, as noted by Morais et al. (2016), and the malignancy of the breast tumor is strongly influenced by staging, that is, the extent of the tumor or its spread when diagnosed early. So, early diagnosis is vitally important for the prognosis.

Lawson (1956), in early thermographic breast studies, stated that early diagnosis of breast cancer could be performed with infrared image. Isard et al. (1971) observed that a cancer compromised breast can produce an increase in infrared emission causing disparity in the thermographic pattern of the breast skin. Nevertheless, infrared imaging to obtain the breast surface temperature distribution has been used in medicine for more than 50 years without a consensus on quantification methodology.

Gautherie and Gros (1980) stated that the rate of cancer detection in reviews of women who were initially considered healthy or with benign mastopathy methods other than thermography was significantly higher in altered thermography. Gautherie (1980) also observed that the superficial thermal pattern of the breasts is related to the metabolism and vascularization of the underlying tissues. The abnormalities observed in the thermal behavior of breast neoplasms are due to the excessive vasodilation caused by nitric oxide originating from neoplastic lesions, as described by Anbar et al. (2001). Hence, the changes found in breast thermography are due to autonomic responses to histochemical changes occurring at the disease site. In resume, infrared image thermography is a non-anatomical method that aims to identify vascular changes with increased blood flow and metabolic activity in the breasts that may be related to abnormalities, even when changes are not yet present in other exams (Brioschi, 2016). Anatomical information, however, cannot yet be analyzed, being the dynamic study of the functional behavior of the breast skin (Frize et al., 2002; Planche, 2004) the ultimate information that infrared image brings to light.

González (2007) proposed a thermal model to try to predict the depth of a tumor. The model was further 
refined and presented by González (2021), with the observation thar the model could be improved by including the internal structure of the breast gland. Another step to assess anatomical information from infrared images was taken by Figueiredo et al. (2019) and Figueiredo et al. (2020), who demonstrated that the geometric centers of the tumors can be estimated with a maximum error of $0.15 \mathrm{~cm}$ with respect to the original location. None of these studies accounted for blood flow.

Metabolic and anatomical data are used to estimate tumor characteristics, as size and location. However, such information is currently evaluated separately in the diagnostic process. It should be noted that all that is physically correlated - that is, metabolic changes are linked to anatomical findings.

Considering the physical connection between metabolism, perfusion, and anatomical structure, it is reasonable to expect that breast anatomical information could be obtained from skin infrared images, and vice versa. Therefore, the objective of this study is to evaluate the possibility of using thermographic data from infrared and computerized tomography for tumor identification and location, including depth.

\section{METHODOLOGY}

To investigate if there are any relations between infrared image and computerized tomography, qualitative data from a case report was analyzed.

The case report data analyzed was: infrared image, mammography, computerized tomography, and ultrasonography guided biopsy. All data was collected from the same individual, during the screening and diagnostic process, by different medical personal involved at the investigation.

The images used in this analysis were prepared to be consistent, and checked to not contain any gaps. Infrared images were analyzed using FLIR Tools $+^{\circledR}$ software v5.13. Mammography and Tomography used DICOM data, and were analyzed by Medical Radiologists, using BIRADS classification, a wellestablished classification method.

The patient gave consent to use her medical data for scientific research.

\section{RESULTS AND DISCUSSION}

A 75-year-old woman, without any complains, was admitted to a routine service with infrared image as shown in Figure 1. The image presents an area of hyper-radiation in the right breast, that suggests increase of metabolic activity.
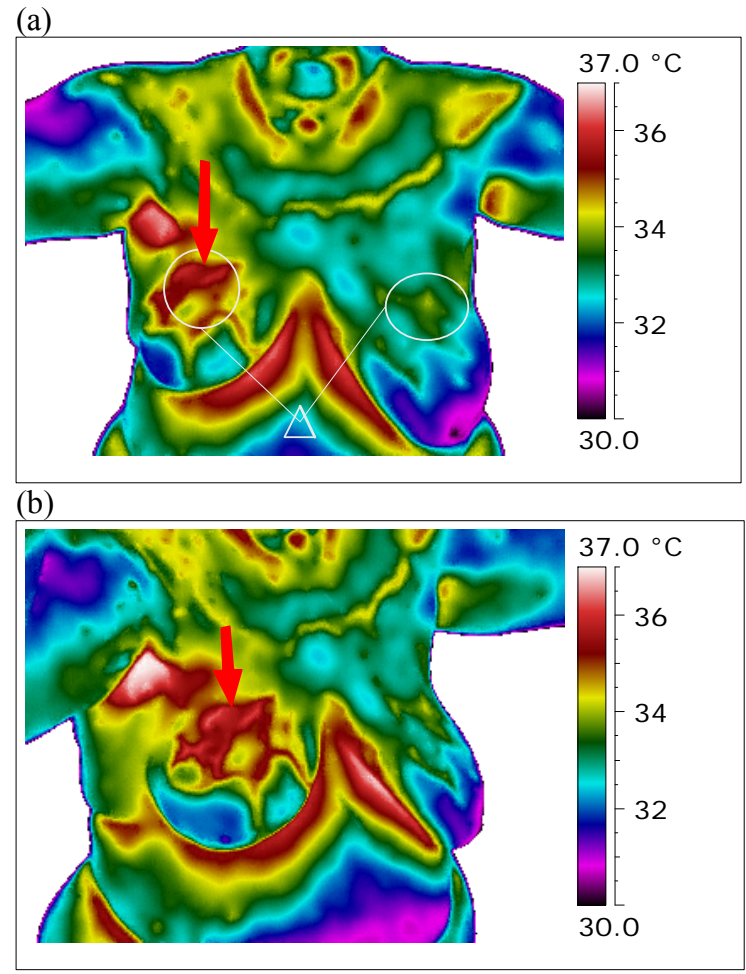

(c)

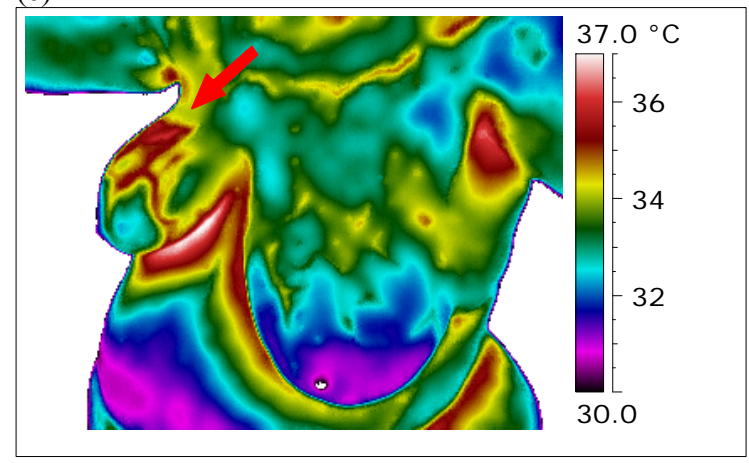

Figure 1. Breast Thermograms: (a) Anterior view; (b) Right oblique view; (c) Left oblique view.

Arrows are included for pointing to suspicious area.

A mammography was also taken and showed abnormalities compatible with BIRADS-5 as it is shown in Figure 2.

The investigation proceeded, and a Computerized Tomography, shown in Figure 3, was conducted, for further characterization of the tumor and to search for lymph nodes - for staging and surgical planning.

Ultrasound guided core biopsy was finally conducted, with Carcinoma ductal “in situ” findings, ending the investigation process and confirming the diagnostic. The patient was eventually submitted to surgical procedure, after more than 3 months of investigations. 


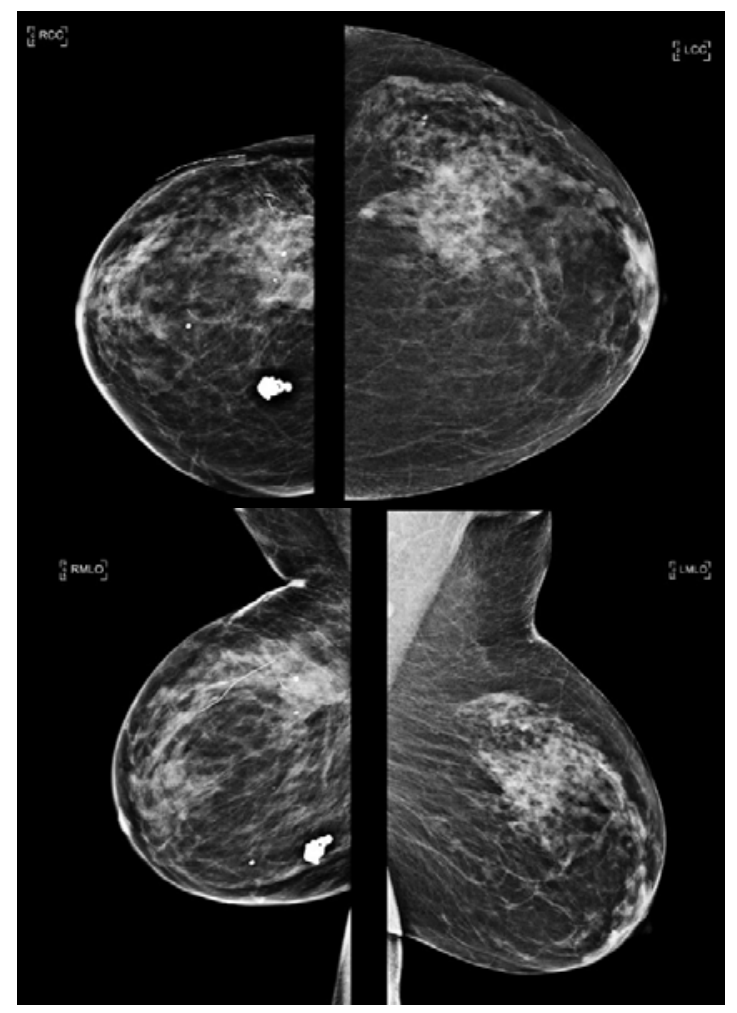

Figure 2. BIRADS-5 Mammography, showing focal irregular asymmetry at upper-lateral posterior third quadrant of the right breast, associated to irregular calcifications.

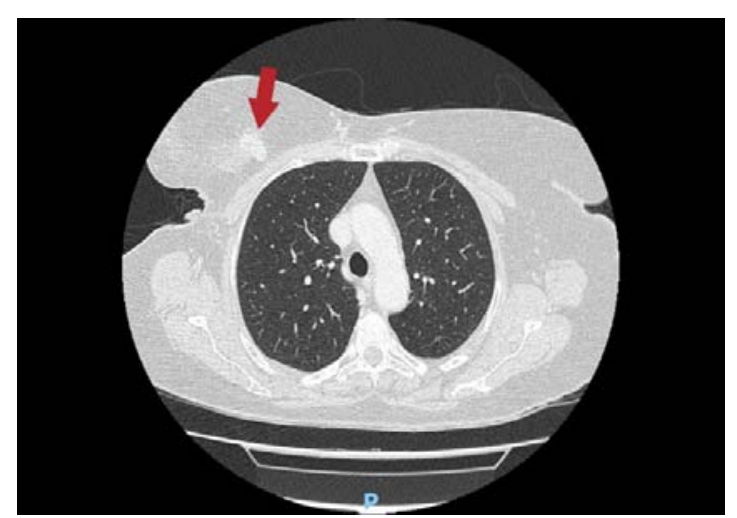

Figure 3. CT: Red arrow shows right breast parenchyma with a deep mass.

Infrared image showed abnormalities in the early stage of analysis. Even without any other information, it could be stated that there were signs of significant changes in breast tissue. And these signs were confirmed by mammography. CT scan, for its part, confirmed not only the disease, but also gave information about the location of the tumor.
Vargas et al. (2009) proposed a normalized methodology to assess infrared image of the breast based on the definition of a dimensionless temperature. A mathematical correlation to estimate breast temperature was also proposed by Souza et al. (2015). The equation could be used to assess infrared breast images, as it provides metabolic information, but also considering the effect of ambient temperature. So, such estimated breast temperature is given by:

$$
\begin{gathered}
\left.\mathrm{T}_{\text {est }}=12.405+\left(\mathrm{T}_{\mathrm{C}} \times 0.548\right)+\mathrm{T}_{\mathrm{R}} \times 0.100\right) \\
\mathrm{T}_{\text {est }}=34.8^{\circ} \mathrm{C}
\end{gathered}
$$

where $\mathrm{T}_{\text {est }}$ is the estimated average temperature of the breast, ${ }^{\circ} \mathrm{C} ; \mathrm{T}_{\mathrm{C}}$ is the patient maximum eye (core) temperature, ${ }^{\circ} \mathrm{C}$; and $\mathrm{T}_{\mathrm{R}}$ is the room temperature, ${ }^{\circ} \mathrm{C}$.

The parameters of the infrared images are shown in Table 1.

Table 1. Breast infrared imaging parameters

\begin{tabular}{|c|c|c|c|}
\hline \multirow{2}{*}{} & \multicolumn{2}{|c|}{ Breast } & \multirow{2}{*}{$\Delta \mathrm{T}_{\mathrm{R}-\mathrm{L}}$} \\
\cline { 2 - 3 } & Right & Left & \\
\hline Mean & $34.9^{\circ} \mathrm{C}$ & $33.2^{\circ} \mathrm{C}$ & $1.7^{\circ} \mathrm{C}$ \\
\hline
\end{tabular}

$\Delta \mathrm{T}_{\mathrm{R}-\mathrm{L}}$ : difference between right and left mean breast temperatures, based on Frize et al. (2002) criteria.

The right breast estimated temperature according to Eq. (1) was $\mathrm{T}_{\text {est }}=34.8{ }^{\circ} \mathrm{C}$. The mean temperature of the right breast was $34.9{ }^{\circ} \mathrm{C}$. Another evaluation was made by simply taking the difference between the mean temperature of both breasts. The result was $\Delta \mathrm{T}_{\mathrm{R}-\mathrm{L}}=1.7{ }^{\circ} \mathrm{C}$, which is highly indicative of abnormality since thermal symmetry is expected with respect to the human body sagittal plane.

The indication of a tumor, based on infrared, mammography, or CT scan, appears clearly in the case studied in this paper. However, the analysis of the three exams is also complementary in terms of locating the tumor inside the breast. Note that the breast infrared image potentially reveals anatomical and physiological changes in the underlying tissues.

Previously, González (2007), Figueiredo et al. (2019), Figueiredo et al. (2020), González (2021), Gautherie (1980a, 1980b) demonstrated that there are correlations among such exams, although in separate analyses. Therefore, it is reasonable to state that, indeed, there is a clear correlation between infrared images and depth, as well as size of the tumor that is worth to be investigated, and possibly propose a methodology to combine CT and infrared imaging for breast tumor diagnosis and accurate localization. A mathematical model could model breast perfusion in time and space, thus tumor depth and morphology in breast cancer could be adequately determined using 
mathematical modeling, infrared imaging, and computerized tomography in complementary actions.

\section{CONCLUSIONS}

A case of breast cancer in a woman was studied in this paper. Infrared image, mammography and computerized tomography were conducted and analyzed, as well as the biopsy confirmation. A physical correlation between infrared image and CT scan findings was detected, which presented an opportunity to improve early breast cancer detection current methods.

The key conclusion is that the location of the geometric center of the breast tumor, from the breast surface skin temperature, could be estimated based on infrared imaging and computerized tomography (CT), provided that a mathematical model is proposed to account for breast blood perfusion, i.e., the physical link between thermal response and anatomic structure. The Volume Element Model (VEM), that combines conservation laws with empirical correlations to quantify several types of flow and energy interactions in a system, and thus produces a simplified breast three-dimensional model (Dilay et al., 2015; Vargas et al., 2001), could be elected as the model to be used to achieve such task.

\section{REFERENCES}

Anbar, M., Milescu, L., Naumov, A., et al., 2001, Detection of Cancerous Breasts by Dynamic Area Telethermometry, IEEE Engineering in Medicine and Biology Magazine, Vol. 20, No. 5, pp. 80-91.

Brioschi, M. L., 2016, Diagnóstico Precoce de Câncer de Mama Não Tem Clínica: Estudo Combinado por Termografia. Pan American Journal of Medical Thermology, Vol. 3, No. 1, pp. 19-24. (in Portuguese)

Dilay, E., Vargas, J. V. C., Souza, J. A., et al., 2015, A Volume Element Model (VEM) for Energy Systems Engineering, International Journal of Energy Research, Vol. 39, No. 1, pp. 46-74.

Figueiredo, A. A. A., Fernandes, H. C., Malheiros, F. C., and Guimaraes, G, 2020, Influence Analysis of Thermophysical Properties on Temperature Profiles on the Breast Skin Surface, International Communications in Heat and Mass Transfer, Vol. 111, p. 104453.

Figueiredo, A. A. A., Do Nascimento, J. G., Malheiros, F. C., et al., 2019, Breast Tumor Localization Using Skin Surface Temperatures from a 2D Anatomic Model Without Knowledge of the Thermophysical Properties, Computer Methods and Programs in Biomedicine, Vol. 172, pp. 65-77.

Frize, M., Herry, C., and Roberge, R, 2002, Processing of Thermal Images to Detect Breast Cancer: Comparison with Previous Work, Proceedings of the Second Joint 24th Annual Conference and the Annual Fall Meeting of the
Biomedical Engineering Society] [Engineering in Medicine and Biology, IEEE, Vol. 2, pp.1159-1160.

Gautherie, M., 1980, Thermopathology of Breast Cancer: Measurement and Analysis of in Vivo Temperature and Blood Flow, Annals of the New York Academy of Sciences, Vol. 335, No. 1 Thermal Chara, pp. 383-415.

Gautherie, M., and Gros, C. M., 1980, Breast Thermography and Cancer Risk Prediction, Cancer, Vol. 45, No. 1, pp. 51-56.

González, F. J., 2007, Thermal Simulation of Breast Tumors, Revista Mexicana de Física, Vol. 53, No. 4, pp. 323-326.

González, F. J., 2021, Thermal Simulations of Cancerous Breast Tumors and Cysts an a Realistic Female Torso, Journal of Biomechanical Engineering, Online ahead of print, pp. 1-40. doi: 10.1115/1.4049957.

INCA, 2015, Diretrizes para a Detecção Precoce do Câncer de Mama no Brasil, Rio de Janeiro: INCA. (in Portuguese)

Isard, H. J., Becker, W., Shilo, R., and Ostrum, B. J., 1971, Breast Thermography after Four Years and 10000 Studies, American Journal of Roentgenology, Vol. 115, No. 4, pp. 811-825.

Lawson, R., 1956, Implications of Surface Temperatures in the Diagnosis of Breast Cancer, Canadian Medical Association Journal, Vol. 75, No. 4, pp. 309-311.

Morais, K. C. C., Vargas, J. V. C., Reisemberger, G. G., et al., 2016, An Infrared Image Based Methodology for Breast Lesions Screening, Infrared Physics \& Technology, Vol. 76, pp. 710-721.

Planche, K., 2004, Breast Imaging in the New Era. Cancer Imaging, Vol. 4, No. 2, pp. 39-50.

Souza, G. G., Brioschi, M. L., Vargas, J. V. C., et al., 2015, Reference Breast Temperature: Proposal of an Equation, Einstein (São Paulo), Vol. 13, No. 4, pp. 518-524.

Vargas, J. V. C., Brioschi, M. L., Dias, F. G., et al., 2009, Normalized Methodology for Medical Infrared Imaging, Infrared Physics \& Technology, Vol. 52, No. 1, p. 42-47.

Vargas, J. V. C., Stanescu, G., Florea, R., and Campos, M. C., 2001, A Numerical Model to Predict the Thermal and Psychrometric Response of Electronic Packages, Journal of Electronic Packaging, Vol. 123, No. 3, p. 200-210. 